\section{EVOLUTION OF WIRE TELEPHONY}

G

EORGE H. GRAY, writing in Electrical Com J munication $(20$, No. $4 ; 1942)$ gives a brief historical review of the progress achieved in telephone wire transmission systems since the early days of the telephone, followed by a discussion of the important economic implications of the newer broad band systems, the 12-channel carrier and coaxial cable. The review is divided into four periods. Plant additions permitted advances during each period in at least three of the following respects : conversation distance, transmission channels obtainable from a pair of conductors, frequency band transmitted and, hence, improved quality and naturalness of conversation, and reliability of service.

The first period, dating from 1876, ended about 1900. Although conversation then was virtually still limited to one per pair of wires, reliability of service and transmitted quality had been improved and the transmitting distance increased considerably, due largely to the use of copper instead of iron wire, better insulators, improved line construction and carefully designed transposition schemes. These changes involved no additions to the inside plant and no increased complications in the outside plant other than the necessity for properly maintaining the transpositions. Using $4.19 \mathrm{~mm}$. copper wire, conversation under favourable conditions was possible by the end of this period over distances of nearly $1,600 \mathrm{~km}$.

The second period, from 1900 to about 1915, saw the introduction of phantom circuits, loading coils and quadded toll cable. These changes resulted in a 50 per cent increase in the circuit capacity of a pair of wires and in slightly more than doubling the transmitting distance of open-wire circuits. The use of underground toll cable, of course, improved the reliability of service. Loading, however, limited the frequency band which could be transmitted, and in some cases this was confined to frequencies below approximately 1,800 cycles, affecting the quality of the transmission accordingly.

The introduction of loading coils also reduced the speed of transmission, thus bringing about potential difficulties from transient and echo effects; this was not particularly objectionable at the time as the circuits involved were comparatively short. The inside plant was made slightly more complex by the phantom repeating coils, and the loading made necessary certain precautions in the maintenance of the outside plant. In general, however, this period added little to plant complexity.

The third period, 1915-37, included the introduction of some radically different and very important types of plant, such as the vacuum tube repeater, the fourwire circuit, one- and three-channel carrier systems, and radio links.

During the last few years of the second period, interesting service results had been obtained with 'mechanical' repeaters, consisting essentially of combination microphones and telephone receivers, but this was abandoned soon after the advent of the vacuum tube repeater. The latter at once more than doubled the transmitting distance of open wire circuits and, by. making possible the removal of open wire loading, permitted the transmission of an increased band width. In cable circuits, repeaters permitted a reduction in the weight of loading and hence an increase in the band width and speed of propagation. The four-wire circuit greatly increased the transmitting range for cable. The three-channel carrier made it possible to obtain nine circuits from an open wire phantom group where only three could be obtained before. By combining transoceanic radio links with land circuits, the transmitting range was increased to such an extent that a conversation around the world was held in 1935 over the route New York-London-Amsterdam-Java-San Francisco -New York, approximately $36,000 \mathrm{~km}$. These advances were not obtained without an increase in the complexity of the plant. It became necessary to maintain repeaters, carrier terminal equipment, radio terminal equipment, special transposition schemes, etc., but, on the whole, no very serious difficulties were encountered. This was due, in no small measure, to special plant personnel training courses conducted at appropriate intervals.

Thus, vacuum tube repeaters and three-channel open wire carrier systems made possible a practically unlimited increase in transmission range and an improvement in transmission quality. Their introduction, moreover, influenced toll-rate decreases appreciably, although outside plant expenditures remained a fairly large factor in the cost of furnishing toll telephone service. Consequently considerable attention was devoted to possibilities of further reductions in outside plant costs.

With near-zero-equivalent circuits already available on conductors approaching the minimum size imposed by mechanical limitations, the most promising solution seemed to be a further increase in the number of circuits obtainable per pair of wires. This involved an increase in the frequency band transmitted and, unfortunately, greater transmission losses and crosstalk due to the application of higher frequencies.

The negative feedback repeater, special transposition schemes for open wire lines, the separation of the 'go' and 'return' conductors in cables, special entrance cables, very careful balancing of all circuits, improved filters, dry metallic modulators, and demodulators, and many other developments made possible the application of higher frequencies to existing types of plant and paved the way for the next period in the history of wire transmission systems.

The fourth period, now well initiated, commenced about 1937 and may be designated as the 'broad band' period of wire transmission. The more important developments include the twelve-channel open wire carrier, the twelve-channel cable carrier and the coaxial cable. Although definite predictions would be somewhat premature, present indications are that progress during this period will exceed even that of the previous period.

Loading performed an important service in improving transmission, but the necessity for transmitting a wider frequency range at higher speeds has now brought about its abandonment for the highest grade of circuits in both open wire and cable.

In the case of twelve-channel systems, it might be thought that elimination of loading and the necessity for frequencies up to $60 \mathrm{kc} . / \mathrm{s}$. would prevent their commercial application. Actually, however, attenua. tion of $1.29 \mathrm{~mm}$. conductors in twelve-channel cable systems is about $2.6 \mathrm{db} . /$ mile at $60 \mathrm{kc} . / \mathrm{s}$. , a value which is quite admissible since it is practicable in this case to work the channels at an attenuation of approximately $60 \mathrm{db}$. per section with repeaters spaced at intervals of about $35 \mathrm{~km}$. Development of these repeaters has progressed to a point where about two out of every three repeater stations generally can be operated unattended. 
The reasons for this high permissible attenuation are very low outside interference at high frequencies and the use of separate cables for the two directions, or, alternatively, a single copper-screened cable to reduce interference between the go-and-return channels. The limit of amplification, or attenuation, is determined by the signal-noise ratio; low outside interference and low cross-talk result in decreased noise. Speech or transmission signals, therefore, may be correspondingly reduced; that is, very high level differences between the beginning and end of a cable section are permissible.

An inherent advantage of twelve-channel systems, highly significant from an economic point of view, results from the importance of installing cables sufficiently large to provide adequately for future growth. Since cable cost represents the greater part of the total outlay for a non-carrier system, the initial investment in cables is ordinarily great, and full realization of returns must be deferred until they are worked at full capacity. In twelve-channel systems the initial investment, on the contrary, is relatively low, and terminal equipment can be added when required; moreover, a better balance between outlay and revenue can be attained over the entire period of use.

It should be emphasized that no attempt was made to reduce the width of the frequency band when the number of channels was increased. Long experience and extensive research have demonstrated the importance of transmitting a relatively wide frequency band. A wide band width, moreover, makes it possible to reduce the transmission level, especially if the noise is low, while if the transmission loss in a long-distance link is reduced to zero, the total allowable losses can be concentrated in the local networks with considerable decrease in their cost. Further, this loss may be increased by several decibels for the same overall effective transmission if the width of the transmitted frequency band is adequately increased. To derive the full benefit from the widening of the band, the subscribers' apparatus-transmitter and receiver-must be capable of producing and reproducing this band; such apparatus has been developed and introduced into commercial use.

The propagation velocity over twelve-channel cable systems is instantaneous for all practical purposes. Even on the longest lines, therefore, speech quality is not appreciably diminished by echoes or other phenomena due to low propagation speed, and therefore lines may be interconnected at will.

Because of the advantages of the twelve-channel carrier cable system, the General Post Office in Great Britain immediately adopted it for its principal toll networks, and the first of such systems was installed in England even before the close of 1936. Shortly thereafter systems were installed in other countries, including the United States, France, Rumania, Sweden, Finland, Holland and Belgium.

For use where very large numbers of telephone circuits were needed and for television, which requires cables capable of transmitting a frequency band of at least $2 \mathrm{mc} . / \mathrm{s}$. , consideration was given to the application of coaxial cables, the speech channels of which are counted in hundreds. Even for cables of small diameter, frequencies of the order of several megacycles per second can be handled and, since telephone channels are spaced at $4 \mathrm{kc} . / \mathrm{s}$., several hundred voice channels can readily be made available.

In Europe, coaxial cables have been laid in Great Britain, France and Germany. In the United States, a $150 \mathrm{~km}$. cable containing two $6 \cdot 7 \mathrm{~mm}$. coaxial lines has been installed between New York and Philadelphia and another four-line $300 \mathrm{~km}$. coaxial cable recently was placed in commercial telephone service between Stevens Point, Wisconsin, and Minneapolis, Minnesota.

The external conductor, at least above $50 \mathrm{kc} . / \mathrm{s}$., serves as a very effective screen against external interference. Hence, very low signal levels, permitting attenuation of $45-60 \mathrm{db}$. per section between repeaters, are acceptable. In a cable of $6 \cdot 7 \mathrm{~mm}$. internal diameter, intervals of about $8 \mathrm{~km}$. between repeaters are thus admissible with a frequency band extending up to $3 \mathrm{mc} . / \mathrm{s}$.

In coaxial cable systems, the total attenuation for a long line is very high; for example, a $1,000 \mathrm{~km}$. coaxial cable $(6.7 \mathrm{~mm}$.), capable of transmitting a frequency band suitable for 300 telephone channels, would have an attenuation of about $4,500 \mathrm{db}$. Since reception levels must be maintained within about $\pm 1 \mathrm{db}$, repeaters must have a high degree of stability, and the net result is a permissible tolerance of about $0.01 \mathrm{db}$. per repeater. Furthermore, from the point of view of distortion and noise, these repeaters must meet stringent requirements. $\mathbf{A}^{*}$ very satisfactory solution is provided by the application of feedback repeaters.

The attenuation of the cable itself, either of the coaxial or twelve-channel type, varies with temperature, so that very long circuits, especially if in aerial cables, necessitate the introduction of compensation devices. For underground cables, manual compensation may be used; for aerial cables, automatic compensation is required due to more rapid temperature fluctuations. Recently a simplified regulating method using devices known as 'thermistors', the resistance of which varies with temperature in the required manner, has been developed and is expected largely to replace the former rather complicated mechānism.

Although the new transmission systems available in this fourth period of development make use of apparatus which at first glance may appear complicated, there seems to be no reason, based on extensive experience to date, to expect any more serious reaction from their application than was encountered with innovations during the other three periods.

The coaxial repeaters, especially, do not require auxiliary equipment. Furthermore, they may be installed in small, simple structures, or be enclosed in metallic housings placed on poles or, in underground chambers. The relatively large number of repeaters necessary is no cause for concern. Experience has demonstrated conclusively that the manufacture of repeaters involving minimum risk of breakdown is a practical proposition; in addition, arrangements are such that either an individual repeater or a complete cable and repeater section may be replaced automatically by a reserve repeater or a complete reserve section.

The new systems represent a most important advance in long-distance communication engineering. Moreover, their development has progressed to the point where they can be considered commercially stabilized to the extent that no radical modification in the structure of cables, repeaters or terminal equipment is to be anticipated. It therefore seems evident that such broad band systems can confidently be taken as the basis for studies of new networks, affording possibilitios of rate reductions and of effecting an extraordinary development in high. 
quality long-distance telephone communications. Further, their advent makes practical, in many instances, provision for the introduction of television networks on an international scale.

Advances during the first two periods were effected largely with material and apparatus placed in the field, that is, 'outside plant' ; those of the third period depended largely on central office equipment. While an important element in progress during the fourth period doubtless must be credited to central office equipment, such as the terminal apparatus for the coaxial and twelve-channel systems, it appears that a new essential factor will be the adaptation of apparatus heretofore regarded as central office equipment to utilization in the field. This new apparatus, as previously indicated, has been embodied in unattended repeater stations.

\section{ASSOCIATION OF UNIVERSITY PROFESSORS AND LECTURERS OF ALLIED COUNTRIES}

\section{GENERAL MEETING}

$\mathrm{T}$ HE Association of University Professors and Lecturers of Allied Countries in Great Britain marked its third general meeting with a whole-day session on December 16. The Association, which now comprises 230 members, works through twelve sections (see Nature, December 12, p. 692), most of which had separate meetings, followed by a general meeting of all members. At this general reunion, reports were presented by the chairmen of groups of sections, and general recommendations made. Thus the deliberations of the individual sections were brought together, to present an inter-Allied view on matters in different domains of actual knowledge. Complete liberty of academic thought and spirit, with such freedom of speech as would be impossible in the countries of continental Europe, characterized the proceedings.

The main points of the aims and work accomplished by the groups of sections were as follow :

Arts : Law, economics, humanities and history, such as studies of comparative law; the position of economic science in the different countries; establishment of a scientific basis for economic planning; the possibility of reaching an agreement on the question of general history ; and considerations relating to an international language.

Science: Inter-Allied collaboration for the establishment of an international academy of medicine; the establishment of an international body of information, and the co-ordination of inventions and scientific discoveries in general; an international research centre; collaboration with the Leith-Ross Committee; the establishment of liaisons with British organizations which are studying the planning and reconstruction of Europe; the examination of problems concerning the moral and material sustenance of scientific men in comparison with the manual worker.

General : Dealing with general subjects and with questions of general interest for university men; for example, contacts between British and foreign scholars in Great Britain during the War ; the promotion of international collaboration after the War; reconstruction and planning of science and learning in the occupied countries, and the problems of the re-education of youth after the War in Allied and enemy countries.

Prof. R. Douglas Laurie, honorary general secretary of the Association of University Teachers, announced that all members of the Association of University Professors and Lecturers of Allied Countries were invited to become honorary members of the Association of University Teachers. This will lead to closer working and social unity between British and Allied professors and lecturers.

In the course of an address by the president of the Association, Prof. S. Glaser (Poland), the various steps were mentioned which the Association has so far been able to make to promote the necessary collaboration between scientific workers and other scholars of the Allied countries. The reconstruction of moral values as well as the rebuilding of institutions of all categories constitutes, he said, one of the aims towards which the Association is exerting its efforts. This is being carried out, so far as possible, with a profound sense, both spiritual as well as cultural, of the importance of European society as a whole after the War.

It was decided at the general meeting, among other matters, that a conference on a fairly large scale on education should be arranged for the early spring 1943, and a sub-committee under the chairmanship of Sir Alfred Zimmern (Oxford) has been appointed for this purpose.

In NATURE of December 12, a list was given of the general officers and chairmen of sections of the Association. The following can now be added to the list. Section 3: Reconstruction of science and learning in the occupied countries (Chairman: Mr. Willard Connely). Section 9 : Medicine as distinct from general science (Chairman : Dr. Jean-Edouard Bigwood). Section 10: Technical Science and Engineering, has been placed in Section 6 (Science).

Thanks to the efforts of the Association, very useful collaboration between members in the field of learning and scientific research is being established among the various professors and lecturers of the Allied countries. It provides an opportunity of establishing unity in the true sense of the word, namely, with intellectual and moral solidarity; a fact the importance of which will be appreciated by scientific men and other scholars of the Allied countries, wherever their interests in the plans and problems of to-morrow may lie.

\section{THE WAIRARAPA (NEW ZEALAND) EARTHQUAKE OF JUNE 24, 1942}

A PRELIMINARY report on some of the seismoA logical aspects of the Wairarapa earthquake of June 24, 1942, has been issued by the Department of Scientific and Industrial Research, New Zealand (Dominion Observatory Bull. S-66, Wellington, New Zealand, September, 1942).

Following a rather strong fore-shock at 8.14 p.m. on June 24, the major shock occurred without further warning at $11 \mathrm{~h} .16 \cdot 5 \mathrm{~m}$. p.m. (New Zealand Daylight Saving Time). Considerable damage to old or poorly constructed buildings occurred at Masterton, where the intensity appeared to be $8+$ on the RossiForel scale. There were no fatal casualties, though minor injuries were caused by falling debris. Intensity 8 on the Rossi-Forel scale was attained over a. 